\title{
To Determine the Correlation between Anthropometric Variables of Obesity and Hypertension at NGMC: A Tertiary Care Hospital
}

\author{
Pant $B N^{1}$, Panta $M^{2}$, Goit $R K^{3}$, Neupane $A^{4}$, Neupane $\mathrm{PP}^{5}$, Bhargava, $\mathrm{P}^{6}$
}

\begin{abstract}
Aim: Obesity is associated with the metabolic risk factors such as high blood pressure, body fat abnormality, and glucose intolerance which may influence the morbidity and mortality due to cardiovascular diseases. The present study is to determine the correlation of common anthropometric indices of obesity with blood pressure among population in mid-western region of Nepal. The result will provide us insight on relevant anthropometric indices for predicting hypertension based on linear correlation calculated from our data. Methods: We screened 500 healthy subjects to study the correlation between anthropometric indices and blood pressure. Result: Our result showed strong correlation between Sum of Skin fold, waist circumference, and waist hip ratio with blood pressure (systolic blood pressure, diastolic blood pressure and mean arterial blood pressure). However some of the anthropometric indices like hip circumference and body mass index did not have significant correlation with blood pressure. Conclusion: Provided obesity related morbidity and mortality is burgeoning in our society it is imperative to identify right indicators of cardiovascular disease for specific population. Relevant anthropometric indices can serve as excellent indicators if used based of scientific validation.
\end{abstract}

Key words: Anthropometric variables, blood pressure, obesity

\section{INTRODUCTION}

Obesity is associated with the metabolic risk factors such as high blood pressure (BP), body fat abnormality, and glucose intolerance which may influence the morbidity and mortality due to cardiovascular diseases $(C V D)^{1,2}$. Most of these deleterious effects are more likely if the excess body fat is mainly stored in the upper body, with abdominal visceral fat being the most critical when evaluating the health risks of obesity ${ }^{1}$. Decreased physical activity, increased consumption of calorie-dense foods and psychosocial stress are few among many factors behind increased obesity among population ${ }^{3}$.

Body Mass Index (BMI) as well as other measures of fat distribution including Waist Circumference (WC) and Waist Hip Ratio (WHR) has been correlated with the cardiovascular risk in many studies ${ }^{4}$. Many of these studies have been done in the American, European and the East Asian population ${ }^{5-7}$. In the past

\footnotetext{
1. Dr. Bhawana Neupane Pant

2. Dr. Manoj Pant

3. Dr. Rajesh Kumar Goit

4. Dr. Ashish Neupane

5. Dr. Ganesh Prasad Neupane

6. Prof. Pushpa Bhargava
}

Address for correspondence:

Dr. Bhawana Neupane Pant

Department of Physiology

Nepalgunj Medical College Teaching Hospital

Chisapani, Banke, Nepal

Email: pant_bhawana@hotmail.com decade, CVD has become burgeoning problem in South Asian population ${ }^{8}$ due to changing diet and lifestyle, it is imperative to have similar studies in this population. So far, only few studies confined to specific population has been conducted the south Asian population. Moreover studies have suggested that people of this origin have increased cardiovascular risk due to more centralized deposition of body fat with higher mean of WC and WHR compared to Europians ${ }^{8-10}$. It has recently been shown that South Asian children have higher body mass adjusted BP levels than white American-Caucasian children ${ }^{11}$. Furthermore, WHO has also lowered the cutoffs for overweight and obesity for the Asian population, which again points to the fact that Asian and especially south Asian population suffers from an overall higher obesity related cardiovascular risk ${ }^{6}$. Therefore understanding the relation of adiposity with CVD in to specific population is essential.

Hypertension (HTN) or high BP is a chronic medical condition in which the BP in the arteries is elevated ${ }^{12}$. The relationship between obesity and HTN is well established ${ }^{13,14}$. Obese subjects display higher BP levels than non-obese individuals even in the normotensive range ${ }^{15}$. Data estimates that around 7.1 million die especially among middle, and old-age adults due to high $\mathrm{Bp}^{16}$. Though many CVD can occur to hypertensive patients BP is mostly common and usually the harbingers most of them. Studies have elucidated the function of adipose tissue derivatives (adipokines and cytokines), neurohumoral pathways, metabolic functions and modulation of pressor/depressor mechanisms. High-caloric intake increases norepinephrine turnover in peripheral tissues, raises resting 
plasma norepinephrine concentrations. High dietary content in fat and carbohydrate has been suggested to acutely stimulate peripheral alpha - and beta-adrenergic receptors, leading to elevated sympathetic activity and HTN. ${ }^{17}$ Abdominal obesity is considered to be more dangerous than general obesity because the visceral fat has been shown to secrete certain cytokines and chemicals that are involved in atherogenesis and alterations in the autonomic balance ${ }^{18}$.

A number of clinical measurements for obesity have been used to determine susceptibility to $C V D^{19}$. The association between HTN and obesity was first recognized through research undertaken in Frahmingham heart study. Even though with the presence of the modern techniques, anthropometric measurements such as height, weight, BMI and WHR etc. are traditionally important method to study the genetic structure and prediction of risk factors of many complex diseases in human health ${ }^{20}$. These anthropometric indices has shown to have an association with many CVD including $B P$, however there seem to be inconsistent finding. This inconsistency in the relation could be due to the nature of relation being population specific and depending on many other factors like dietary culture, exercise habits, lifestyle and overall environment $\mathrm{t}^{20}$.

The different studies have tried to relate the relationship of BMI and WHR to $\mathrm{BP}^{21-24}$. Therefore, one basic question raises that which one of the anthropometric measurements could be an appropriate to track the elevated BP in general population. Our study aims to answer if all measures of anthropometric variable has similar correlation with BP irrespective of gender and age. This will lead us to determine the relationship between these measures and the BP; and thus to identify their effectiveness in screening the individuals with higher BP.

\section{MATERIAL AND METHODS}

This cross sectional prospective study was conducted in Nepalgunj Medical College Teaching Hospital (NGMCTH) Subjects of this study were patients attending outpatient department (OPD) of the department of medicine of NGMCTH, Nepalgunj from date 2015-5-3 to 2016-6-8. The healthy subjects of the age range 30 to 55 years who gave the consent were included in the study. The subjects with the history of HTN in past 5 years were excluded from our study.

The anthropometric measurements were measured by standard procedures. The height was measured by stadiometer with subjects having their shoes removed ${ }^{25}$. The measuring tape was used to measure the WC at the level of the narrowest point between the lowest rib margin and the iliac $\mathrm{crest}^{26,27}$. The hip circumference $(\mathrm{HC})$ was measured at the level of maximum extension of the buttocks when subject is standing straight with arms by sides and feet together. The measurement was made with a stretch-resistant tape that was wrapped snugly around the buttocks in a horizontal plane. The height, $\mathrm{HC}$ and WC measurement were recorded to the nearest $0.1 \mathrm{~cm}$. The body weights of the subjects was measured in light clothing, without shoes ${ }^{25}$. BMI was determined by dividing weight in kilogram $(\mathrm{kg})$ by height in square meter $\left(\mathrm{m}^{2}\right)^{28}$. The WHR was determined by dividing the WC by the $\mathrm{HC}^{26,27}$ The international standard for anthropometric assessment published by the International Society for the Advancement of Kianthropometry, was used for measuring the skin folds. ${ }^{26,29}$ Measurement were recorded to the nearest $0.05 \mathrm{~cm}$ by using the slim guide skinfold caliper. ${ }^{26,29}$ The measurements of systolic(SBP) and diastolic blood pressure (DBP) were taken with the help of mercury sphygmomanometer in a sitting position when subjects are in fully resting state. Mean arterial blood pressure (MAP) was calculated for each of the two readings taken for $\mathrm{SBP}$ and $\mathrm{DBP} \mathrm{P}^{30-32}$.

\section{Data Analysis}

Microsoft Excel and Statistical program available in SPSS 16 (Statistical Package for Social Science) for Windows computer operating systems are utilized in this analysis. BMI, WHR, subcutaneous fat, $\mathrm{HC}$, WC were compared with SBP, DBP, MAP using Pearson Correlation coefficient test. The data analysis were considered significant at $\mathrm{P}<0.05$.

\section{RESULTS}

500 subjects qualifying the inclusion criteria were screened for anthropometric variables of obesity and BP. Most of the subjects (52.6\%) in the study are in the age range (36 - 45yrs) as shown in the demographic provided in the Table I.

\begin{tabular}{|c|c|c|c|}
\hline $\begin{array}{c}\text { Age } \\
\text { (years) }\end{array}$ & $\begin{array}{c}\text { Males } \\
(\mathbf{n}-\mathbf{2 7 8})\end{array}$ & $\begin{array}{c}\text { Females } \\
(\mathbf{n}=\mathbf{2 2 2})\end{array}$ & $\begin{array}{c}\text { Total } \\
(\mathbf{n}=\mathbf{5 0 0})\end{array}$ \\
\hline $30-35$ & 45 & 29 & 74 \\
\hline $36-40$ & 82 & 50 & 132 \\
\hline $41-45$ & 62 & 69 & 131 \\
\hline $46-50$ & 52 & 38 & 90 \\
\hline $51-55$ & 37 & 36 & 73 \\
\hline
\end{tabular}

Table I: Distribution of subjects according to age

\begin{tabular}{|l|c|c|c|}
\hline \multicolumn{1}{|c|}{ BP (mmHg) } & $\begin{array}{c}\text { Male } \\
(\mathbf{n = 2 7 8})\end{array}$ & $\begin{array}{c}\text { Female } \\
(\mathbf{n = 2 2 2})\end{array}$ & $\begin{array}{c}\text { Total } \\
(\mathbf{n = 5 0 0 )}\end{array}$ \\
\hline Normotensive (<93.3) & 107 & 155 & 262 \\
\hline Prehypertension (93.3- 106.7) & 138 & 51 & 189 \\
\hline Stage 1 HTN (107- 119) & 30 & 15 & 45 \\
\hline Stage 2 HTN (> 120) & 3 & 1 & 4 \\
\hline
\end{tabular}

Correlation significant at ${ }^{*} p<0.05,{ }^{* *} p<0.001$

Table II: Distribution of subjects according to classification of BP (MAP) 
Pant et al.: To Determine the Correlation between Anthropometric Variables of Obesity and Hypertension Among Mid-Western Population of Nepal

The distribution of subjects according to the blood pressure classification in the Table II depicts that $52.4 \%, 37.8 \%, 9.0 \%$ and $0.8 \%$ of total population were normotensive, prehypertensive, stage $1 \mathrm{HTN}$ and stage $2 \mathrm{HTN}$ respectively. The distribution also clearly shows the prevalence of HTN (prehypertension, stage 1 HTN and stage 2 HTN) in male population (61.5\%) compared to female population (30.2\%).

Table III provides the mean and standard deviation (S.D) of the basic measurements in male and female subjects. The fourth column in the table gives $p$-value, where value of less than 0.05 indicates significant difference between male and female. The result shows that WHR, MAP, HC and Abd. SF were significantly

\begin{tabular}{|c|c|c|c|}
\hline Parameters & $\begin{array}{c}\text { Normotensive } \\
\text { (mean } \pm \text { s.d) }\end{array}$ & $\begin{array}{c}\text { Hypertensive } \\
\text { (mean } \pm \text { s.d) }\end{array}$ & p-value \\
\hline DBP & $84.55 \pm 8.34$ & $94.18 \pm 10.91$ & $0.01^{*}$ \\
\hline SBP & $117.22 \pm 7.12$ & $132.22 \pm 7.02$ & $0.03^{*}$ \\
\hline MAP & $92.78 \pm 3.39$ & $105.18 \pm 6.56$ & $0.01^{*}$ \\
\hline BMI & $27.95 \pm 2.96$ & $32.87 \pm 3.39$ & $0.04^{*}$ \\
\hline WHR & $0.88 \pm 0.15$ & $0.99 \pm 0.11$ & $0.01^{*}$ \\
\hline WC & $100.44 \pm 9.2$ & $114.04 \pm 11.56$ & $0.00^{* *}$ \\
\hline HC & $111.65 \pm 6.8$ & $120.91 \pm 7.55$ & 0.06 \\
\hline SSF & $30.30 \pm 5.16$ & $37.49 \pm 6.80$ & $0.02^{*}$ \\
\hline Abd. SF & $45.56 \pm 4.50$ & $65.65 \pm 7.00$ & $0.00^{* *}$ \\
\hline
\end{tabular}

Correlation significant at * $p<0.05,{ }^{* *} p<0.001$

Table III: BP and anthropometric indices among participants according to the presence of hypertension different in both gender. Mean values of height, weight, $\mathrm{HC}$, WC, SSF, abdominal skinfold and MAP were found to be significantly higher in males as compared with females. The mean values of all the skinfold thicknesses, that is, biceps, triceps, subscapular, and suprailiac were higher among females than males. Similarly mean values of BMI and fat percentage were also higher among females.

The linear correlation between anthropometric indices and the BP (SBP, DBP and MAP) is presented in Table IV and Table V. The result clearly indicates that $\mathrm{BMI}$ does not have significant correlation with most of anthropometric indices except DBP which has significant correlation. Age was found to have positive and statistically significant correlation with both SBP and DBP among males as well as females subjects (data not shown). The strongest correlation of BP was reported with SSF, WC and WHR. Overall the DBP has stronger correlation with anthropometric variables compared with SBP.

The anthropometric variables included in this study provides estimation of the fat percentage, so the Table VI provides the correlation between anthropometric variables (BMI, WHR, WC and $\mathrm{HC}$ ) and SSF (estimation of body fat percentage). The results show that the $\mathrm{BMI}, \mathrm{WHR}, \mathrm{WC}$ and $\mathrm{HC}$ is highly correlated with SSF. WHR and WC has strongest correlation with SSF with $p$-value of 0.01 and 0.04 respectively in males. However the WC has the strongest correlation with the SSF in females with the $p$ value of 0.03 . The BMI and WHR did not have significant correlation with SSF among female subjects.

\section{DISCUSSION}

Many studies have reported the relation of BP, one of the most common CVD with anthropometric parameters such as BMI, WHR, WC, HC, SF etc ${ }^{1-4}$. There are inconsistencies in their

\begin{tabular}{|c|c|c|c|c|c|c|c|c|c|}
\hline & \multicolumn{3}{|c|}{ BMI } & \multicolumn{3}{c|}{ WHR } & \multicolumn{3}{c|}{ HC } \\
\hline & Male & Female & Overall & Male & Female & Overall & Male & Female & Overall \\
\hline SBP & 0.08 & 0.09 & 0.08 & $0.04^{*}$ & 0.06 & $0.04^{*}$ & 0.08 & 0.10 & 0.11 \\
\hline DBP & $0.04^{*}$ & 0.08 & 0.07 & $0.03^{*}$ & $0.01^{*}$ & $0.03^{*}$ & 0.21 & 0.32 & 0.10 \\
\hline MAP & 0.66 & 0.07 & 0.07 & $0.03^{*}$ & $0.02^{*}$ & $0.04^{*}$ & 0.08 & 0.12 & 0.09 \\
\hline
\end{tabular}

Correlation significant at *p<0.05, ${ }^{* *} p<0.001$

Table IV: Linear correlation between anthropometric indices (weight, BMI and WHR) and systolic and diastolic blood pressure

\begin{tabular}{|c|c|c|c|c|c|c|c|c|c|}
\hline & \multicolumn{3}{|c|}{ WC } & \multicolumn{3}{c|}{ SSF } & \multicolumn{3}{c|}{ Abd. SF } \\
\cline { 2 - 10 } & Male & Female & Overall & Male & Female & Overall & Male & Female & Overall \\
\hline SBP & $0.04^{*}$ & 0.06 & 0.07 & $0.02^{*}$ & $0.04^{*}$ & $0.02^{*}$ & $0.01^{*}$ & $0.01^{*}$ & $0.01^{*}$ \\
\hline DBP & $0.03^{*}$ & 0.05 & $0.03^{*}$ & $0.00^{* *}$ & $0.03^{*}$ & $0.04^{*}$ & $0.00^{* *}$ & $0.00^{* *}$ & $0.00^{* *}$ \\
\hline MAP & $0.03^{*}$ & $0.02^{*}$ & $0.04^{*}$ & $0.00^{* *}$ & $0.02^{*}$ & $0.01^{*}$ & $0.00^{* *}$ & $0.04^{*}$ & $0.00^{* *}$ \\
\hline
\end{tabular}

Table V: Linear correlation between anthropometric indices (HC, WC and SSF) and systolic and diastolic blood pressure 
Pant et al.: To Determine the Correlation between Anthropometric Variables of Obesity and Hypertension Among Mid-Western Population of Nepal

Fold (SSF) with anthropometric variables

\begin{tabular}{|c|c|c|}
\hline \multirow{2}{*}{ Parameter } & \multicolumn{2}{|c|}{ SSF } \\
\cline { 2 - 3 } & Male & Female \\
\hline BMI & 0.05 & 0.2 \\
\hline WHR & $0.01^{*}$ & 0.65 \\
\hline WC & $0.04^{*}$ & 0.03 \\
\hline HC & 0.53 & 0.11
\end{tabular}

Table I : Age distribution of cases by age

Table VI: Correlation of sum of skin

finding, which can be ascribed to the diversity in sample population. Additionally, there might be some methodological differences behind inconsistency in results. However one should not undermine that correlation of anthropometric variable with fitness parameters such as $\mathrm{BP}$ and pulse rate can be affected by lifestyle, exercise habits, over all environment and genetics among the population. Therefore our study was aimed to determine the relationship of parameters in small cohort of population in Nepal, where any of such studies has not been reported.

The study screened 880 random subjects attending NGMCTH; among which 500 subjects who met the inclusion criteria were selected. Among 500 subjects $52.4 \%, 37.8 \%, 9.0 \%$ and $0.8 \%$ of total population were normotensive, prehypertensive, stage 1 HTN and stage 2 HTN respectively. Provided the subjects included in this study were not diagnosed with HTN in past five years. Our calculated result, where $48 \%$ of sample population were in hypertensive range indicates the lack of awareness as well as it highlights the impeding problem of hypertension in the population.

The present study provides the correlation of BMI, WC, WHR, SSF and Abd SF with BP suggesting the better anthropometric for predicting HTN in both sexes. The results presented in the table IV and V indicates that the SSF, Abd. SF, WHR and WC had the strongest correlation with $\mathrm{BP}$ in both male as well as in female. However, the $\mathrm{HC}$ did not have significant correlation with BP among female subjects. Our results as shown in table also indicates that DBP has strongest correlation with many of anthropometric variables (WHR, WC, HC and BMI). The DBP is the direct measure of total peripheral resistance and is less fluctuating that SBP which is mainly a direct measure of cardiac output $^{33}$. Moreover SSF is the indirect measure of total fat percentage and our result in table VI shows that WC has strong and significant correlation with SSF. However WHR is correlated with SSF only among female subjects. Therefore from the combined result from table IV, V and VI we can conclude that
SSF abdominal skinfold has strong and significant correlation with HTN thus can be recommended as a useful screening tool for predicting HTN. However whenever measuring skin fold is not feasible WC and WHR can be reliable indicator of HTN based on our results. Our result also confirms with some of other studies that have found that WHR have been found to be a more efficient predictor of HTN than the BMI ${ }^{34.40}$. The result also indorses the statement from one of research article that if obesity is redefined using WHR instead of BMI, the proportion of people categorized as at risk of heart attack worldwide increases threefold ${ }^{41}$. Therefore our study have found that WC and WHR are good indicator of cardiovascular risk factors, body fat distribution and HTN and should be incorporated into a public message and awareness programs.

\section{CONCLUSION}

Body fat percentage measured by skinfold thickness method predict blood pressure level better than BMI in this population. High WC \& WHR should be used as a measure of increased risk for hypertension among this population and should be incorporated into a public message and awareness programs.

\section{REFERENCES}

1. Lahti-Koski M. Body mass index and obesity among adults in Finland [Online]. 2001 Nov 9 [cited 21 Dec 2013]; Available from: URL:http://ethesis.helsinki.fi/julkaisut/laa/kansa/vk/lahtikoski/bodymass.pdf

2. Oda E, Kawai R. Age and gender-related differences in correlations between abdominal obesity and obesity-related metabolic risk factors in Japanese. Intern Med 2009;48:497-02.

3. Gupta R, Rastogi P, Sarna M, Gupta VP, Sharma SK, Kothari K. Body-mass index, waist-Size, waist-hip ratio and cardiovascular risk factors in urban subjects. JAPI 2007 Sep;55:621-7.

4. Knowles KM, Paiva LL, Sanchez SE, Lopez LR, Yasuda MB, Yanez ND et al. Waist Circumference, Body Mass Index, and Other Measures of Adiposity in Predicting Cardiovascular Disease Risk Factors among Peruvian Adults. Int J Hypertens. 2011; 2011: 931402

5. Rubenstein AH. Obesity: A Modern Epidemic. Trans Am Clin Climatol Assoc. 2005; 116: 103-113.

6. Enas EA. Coronary artery disease epidemic in Indians: a cause for alarm and call for action. J Indian Med Assoc 2000;98:694-02.

7. Gupta M, Brister,S, Verma S. Is South Asian ethnicity an independent cardiovascular risk factor?. Can J Cardiol. 2006 Mar; 22(3): 193-197.

8. Paul P, Thomas G, George AB, Yuling H, Judith SS, Xavier FS, Robert HE. Obesity and Cardiovascular Disease: pathophysiology, evaluation, and effect of weight Loss: an update of the 1997 American Heart Association Scientific Statement on Obesity and Heart Disease from the Obesity Committee of the Council on Nutrition, Physical Activity, and Metabolism. 2006 Feb 14;113(6):898-918. Epub 2005 Dec 27: DOI:10.1161/CIRCULATIONAHA.106.171016

9. Keigue PM, Saha B, Marmot MG. Relation of central obesity and insulin resistance with prevalence and cardiovascular risk in 
South Asian. Lancet 1991;337:382-7.

10. Ghosh A, Bose K, Das AB. Comparison of anthropometric characteristics between normotensive and hypertensive individuals among a population of Bengalee hindu elderly men in Calcutta. India J R Soc Health 2000;120:100-6.

11. Jafar TH, Islam M, Poulter N, Hatcher J, Schmid CH, Levey AS et al. Children in South Asia have higher body mass-adjusted blood pressure levels than white children in the United States: a comparative study. Circulation. 2005 Mar 15;111(10):1291-7.

12. Sanya AO, Ogwumike OO, Ige AP, Ayanniyi OA. Relationship of waist-hip ratio and body mass index to blood pressure of individuals in Ibadan north local government. AJPARS 2009 June;1(1):7-11.

13. Kotsis V, Stabouli S, Bouldin M, Low A, Toumanidis S, Zakopoulos $\mathrm{N}$. Impact of obesity on 24-h ambulatory blood pressure and hypertension. Hypertension 2005;45: 602-7.

14. Stabouli S, Kotsis V, Papamichael C, Constantopoulos A, Zakopoulos N. Adolescent obesity is associated with high ambulatory blood pressure and increased carotid intimal medial thickness. J Ped 2005; 147:651-6.

15. Mancia G, Backer GD, Dominiczak A, Cifkova R, Fagard R, Germano G, et al. The guideline for the Management of Arterial Hypertension: the task force for the management of arterial hypertension of the European Society of Hypertension (ESH) and of the European Society of Cardiology (ESC). J Hypertens 2007;25:1105-87.

16. Lakka HM, Laaksonen DE, Lakka TA, Niskanen LK, Kumpusalo E, Tuomilehto $J$ et al. The metabolic syndrome and total and cardiovascular disease mortality in middle aged men.JAMA 2002 Dec;288:2709-16.

17. Grassi G, Seravalle G, Cattaneo BM, Bolla G, Lafranchi A, Colombo $M$ et al. Sympathetic activation in obese normotensive subjects. Hypertension 1995;25:560-563.

18. Katagiri H, Yamada T, Oka Y. Adiposity and cardiovascular disorders: disturbance of the regulatory system consisting of humoral and neuronal signals. Circ Res 2007;101(1):27-39.

19. Cameron AJ, Welborn TA and Zimmet PZ. Overweight and obesity in Australia: the 1999-2000 Australian diabetes, obesity and lifestyle study. Med J Aust2003;178:427-32.

20. Visscher TL and Seidell, JC. The public health impact of obesity. Annu Rev of Public Health;22:355-75.

21. Dua S, Bhuker M, Sharma P, Dhall P, Kapoor S. Body Mass Index Relates to Blood Pressure Among Adults. N Am J Med Sci. 2014 Feb; 6(2): 89 95.doi: 10.4103/1947-2714.127751.

22. White FM, Pereira LH, Garner JB. Associations of body mass index and waist: hip ratio with hypertension. CMAJ. 1986 Aug 15; 135(4): 313-320. PMC1491450

23. Pantelic $S$, Kostic R, Djuraskovic R, Uzunovic $S$, Milanovic $Z$ ,Trajkovic N. Relationship between physical fitness, bmi, whr and hypertension in elderly men and women. SJPH. Zdrav Var 2013; 52:275-284

24. Zafar S, Haque I, Rasheed AB, Mirza GH, Shafiq F, Rehman A, Ullah N. Relationship of body mass index and waist to hip ratio measurement with hypertension in young adult medical students. Pak J of Medical Sci July-Sept 2007; 23: 4

25. Lohman TG, Roche AF, Martorell R, editors. Anthropometric Standardization Reference Manual. Champaign II: Human Kinetics; 1988. p. 143-9.
26. Dudeja V, Mistra A, Pandey RM, Devina G, Kumar G Vickram NK. $\mathrm{BMI}$ does not accurately predict overweight in Asian Indians in Northern India. British J Nutr 2001;86: 105-12.

27. Seidell JC, Perusse L, Despres JP, Bouchard C. Waist \& Hip circumferences have independent \& opposite effects on cardiovascular disease risk factors: The Quebec family study. Amer J Clin Nutr 2001 Sept;74(3):315-21.

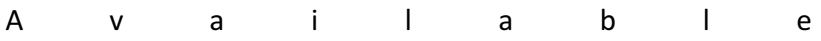
from:URL:http://proxy.lib.umich.educ:2557/egi/content/full/74 $13 / 3$

28. Nichols SD, Cadogan, F. Anthropometric reference values in an Apro-Caribben adolescent population. Amer J Human Biol 2008;20:51-8.

29. Smith C, Rinderknecht K. Obesity correlates with increased blood pressures in urban native American youth. Amer J of Hum Biol 2003;15:78-90.

30. Londe S, Goldring D. High blood pressure in children. Problems and Guidelines for evaluation and treatment. Am J Cardial 1976;37:650-7.

31. Pal GK, Pal P. Text book of practical Physiology. 3rd ed. Hydrabad: Universities Press (India) Pvt. Ltd.; 2011. p.174.

32. Weinsier RL, Norris DJ, Birch R, Bernstein RS, Wang J, Yang MU et al. The relative contribution of body fat and fat pattern to blood pressure level. J Amer Heart Assoc 1985;7:578-85.

33. Pal GK, Pal P, Nanda N. Text book of Medical Physiology. $2^{\text {nd }}$ ed. Delhi: Tarun Ahuja for Ahuja Publishing House; 2012. p. 647.

34. Esmaillzadeh A, Mirmiran P, Azizi F. Waist-to-hip ratio is a better screening measure for cardiovascular risk factors than other anthropometric indicators in Tehranian adult men. Int J Obes Relat Metab Disord 2004 Oct;28(10):1325-32.

35. Ko GT, Chan JC, Woo. Simple anthropometric indexes and cardiovascular risk factors in Chinese. Int J Obes Relat Metab Disord. 1997 Nov;21(11):995-1001.

36. Guagnano MT, Ballone E, Colagrande V. Large waist circumference and risk of hypertension. Int J Obes Relat Metab Disord. 2001 Sep;25(9):1360-4.

37. Flier JS, Flier EM. Obesity. Harrison's principles of internal medicine. 16thed. New York: McGraw Hill; 2005. p.422-7.

38. Rivero J. Waist/hip ratio and vascular risk factors in obese and not obese individuals. An Med Interna 1997 Jan;14(1):3-8.

39. Zhao $\mathrm{WH}, \mathrm{Xu} \mathrm{HO}$, Zhang $X$, et al. The association of BMI and WHR on blood pressure levels and prevalence of hypertension in middle-aged and elderly people in rural China. Biomed Environ Sci 2000 Sep;13(3):189-97.

40. Hall JE. Guyton and Hall textbook of medical physiology. $12^{\text {th }}$ ed. Philadelphia: Elsevier Inc.; 2011. p. 225.

41. Waist-Hip Ratio [Online]. 2010 Oct 11 [cited 2015 Dec 21]; [4 screens ]. Ava i l a ble from; URL: http://en.wikipedia.org/wiki/Waist\%E2\%80\%93hip_ratio. 